\title{
Prospective Analysis of Coagulopathy Associated with Isolated Traumatic Brain Injury and Clinical Outcome
}

\author{
Gopal Krishna ${ }^{1}$ Varun Aggarwal ${ }^{1} \quad$ Ishwar Singh ${ }^{1}$ \\ ${ }^{1}$ Department of Neurosurgery, Pt. B.D. Sharma Postgraduate \\ Institute of Medical Sciences, Rohtak, Haryana, India
}

\begin{abstract}
Address for correspondence Gopal Krishna, MCh, Department of Neurosurgery, Pt. B.D. Sharma Postgraduate Institute of Medical Sciences, Rohtak, Haryana, 124001, India (e-mail: gopalblue222@gmail.com).
\end{abstract}

\begin{abstract}
Keywords

- coagulopathy

$-\mathrm{TBI}$

- DIC score

- head injury

Introduction Traumatic brain injury (TBI) affects the coagulation pathway in a distinct way than does extracranial trauma. The extent of coagulation abnormalities varies from bleeding diathesis to disseminated thrombosis.

Design Prospective study.

Methods The study included 50 patients of isolated TBI with cohorts of moderate (MHI) and severe head injury (SHI). Coagulopathy was graded according to the values of parameters in single laboratory. The incidence of coagulopathy according to the severity of TBI and correlation with disseminated intravascular coagulation (DIC) score, platelets, prothrombin time (PT), activated partial thromboplastin time (APTT), D-dimer, and fibrinogen was observed. The comparison was also made between expired and discharged patients within each group. It also compared coagulation derailments with clinical presentation (Glasgow Coma Scale [GCS]) and outcome (Glasgow Outcome Scale [GOS]).

Results Road traffic accident was the primary (72\%) mode of injury. Fifty-two percent had MHI and rest had SHI. Eighty-four percent of cases were managed conservatively. The mean GCS was 12.23 and 5.75 in MHI and SHI, respectively. Sixty-two percent of $\mathrm{MHI}$ and $96 \%$ of the patients with $\mathrm{SHI}$ had coagulation abnormalities. On statistical analysis, DIC score $(p<0.001)$ strongly correlated with the severity of head injury and GOS. PT and APTT were also significantly associated with the severity of TBI. In patients with moderate TBI, D-dimer and platelet counts showed association with clinical outcome. Fibrinogen levels did not show any statistical significance. The mean platelet counts remained normal in both the groups of TBI. The mean GOS was 1.54 and 4.62 in $\mathrm{SHI}$ and $\mathrm{MHI}$, respectively.

Conclusion Coagulopathy is common in isolated TBI. The basic laboratory parameters are reliable predictors of coagulation abnormalities in TBI. Coagulopathy is directly associated with the severity of TBI, GCS, and poor outcome.
\end{abstract}

DOI https://doi.org/ 10.1055/s-0041-1728989 ISSN 2277-954X
(C)2022. Neurological Surgeons' Society of India.

This is an open access article published by Thieme under the terms of the Creative Commons Attribution-NonDerivative-NonCommercial-License, permitting copying and reproduction so long as the original work is given appropriate credit. Contents may not be used for commercial purposes, or adapted, remixed, transformed or built upon. (https://creativecommons.org/licenses/by-nc-nd/4.0/).

Thieme Medical and Scientific Publishers Pvt. Ltd. A-12, 2nd Floor, Sector 2, Noida-201301 UP, India 


\section{Introduction}

Traumatic brain injury (TBI) is a global health burden that affects people of all socioeconomic groups. It is a leading cause of mortality, morbidity, and disability in patients of trauma. Coagulopathy associated with TBI is well known for a long time; however, the exact pathophysiology is still poorly understood. ${ }^{1,2}$

However, several reports suggest coagulation derailments following TBI occur secondary to the release of tissue factor which is the physiological initiator of local and systemic coagulation and fibrinolytic pathways. Coagulopathy following TBI is a dynamic process of hypercoagulability followed by hemorrhagic diathesis. ${ }^{1,3-5}$ The hypercoagulable state may be generalized in the form of disseminated intravascular coagulation (DIC) or localized with the development of microthrombi in the penumbra of contusion. The other mechanisms include platelet dysfunction, DIC, and activation of protein C pathways secondary to hypoperfusion. ${ }^{3,4,6-8}$

The state of DIC and consequent intravascular thrombosis in microvasculature can result in ischemic brain damage. This resultant secondary injury may lead to brain edema, progression of contusions, and hematoma. DIC can also be fulminant accompanied by uncontrolled hemorrhage, widespread necrosis, multiple organ failure, and death. The coagulation disorder in TBI is hence associated with poor outcome. Various authors in developed countries have reported the incidence of coagulation disorders in TBI. ${ }^{8-21}$ However, data regarding the same is lacking for most low- and middle-income countries.

The extent of impact on TBI by the coagulation derailments is largely unknown. The present study was aimed to study the incidence of coagulopathy in TBI. The study also attempted to explore the extent of coagulation profile derangements, its correlation with the severity of TBI, and clinical outcome.

\section{Materials and Methods}

The study is of prospective design and compared incidence of coagulopathy in moderate and severe TBI. It also compared DIC score and other laboratory parameters among discharged and expired patients of both moderate head injury (MHI) and severe head injury (SHI).
The study was performed on patients with isolated head injury at a government referral center in North India. A total of 50 patients in the age group of 20 to 70 years were studied. Patients having other associated injuries (extracranial trauma) like long bone fractures, chest injuries, and abdominal injuries were not included in the study. Those with preexisting coagulopathy or on anticoagulants, hypertension, diabetes, hepatic and renal dysfunction, or any other comorbidities were excluded.

All the selected patients were divided into subgroups of MHI and SHI based upon their Glasgow Coma Scale (GCS). Patients with GCS of 9 to 13 were classified as having MHI and $<8$ as SHI.

Investigations including complete hemogram, prothrombin time (PT), activated partial thromboplastin time (APTT), D-dimers, fibrinogen, computed tomography head, and ultrasonography of chest and abdomen were done. The blood was collected at the triage area itself upon arrival of the patient without any delay and processed immediately.

All the blood investigations used to calculate DIC score (modified) were based on parameters as outlined by the International Society on Thrombosis and Haemostasis (ISTH) scoring system. APTT was also evaluated. The result of all the above blood investigations was graded on a score of 0 to 3 according to the range of normal values for a healthy population in the same laboratory (-Table $\mathbf{1}$ ). The sum of all the five blood investigations for a given patient was regarded as a DIC score. After calculation of the DIC score, the severity of DIC was graded as shown in - Table 1 .

Coagulopathy was defined as platelet counts less than 100,000 and PT > 15 seconds, APTT > 35 seconds, or a DIC score of more than 4 . The outcome in each group was measured as per the Glasgow Outcome Scale (GOS).

\section{Observations and Results}

The study included 50 patients with isolated head injury. Age and sex distribution of patients is shown in - Fig. 1.

\section{Mechanism of Injury}

The road traffic accident (RTA) was the most common mode of injury. Thirty-six patients (72\%) sustained head injury by RTA. Six patients sustained the injury by assault (12\%) and another six patients by fall. In $4 \%$ of cases mode of injury was unknown as these patients were found under unknown circumstances.

Table 1 Laboratory parameters with scoring system

\begin{tabular}{|l|l|l|l|l|l|l|l|}
\hline Severity & $\begin{array}{l}\text { Platelet count } \\
\text { (in lacs) }\end{array}$ & $\begin{array}{l}\text { PT (in } \\
\text { seconds) }\end{array}$ & $\begin{array}{l}\text { APTT (in } \\
\text { seconds) }\end{array}$ & $\begin{array}{l}\text { D-dimer } \\
\text { (ng/mL) }\end{array}$ & $\begin{array}{l}\text { Fibrinogen } \\
\text { (g/L) }\end{array}$ & $\begin{array}{l}\text { Score for } \\
\text { laboratory } \\
\text { parameter }\end{array}$ & DIC score \\
\hline Normal & $>1.5$ & 13.5 & $26-34$ & $<1,000$ & $>2$ & 0 & $0-3$ \\
\hline Mild derangement & $1-1.5$ & $13.5-15.0$ & $>34$ & $1,000-2,000$ & $<2$ & 1 & $3-6$ \\
\hline $\begin{array}{l}\text { Moderate } \\
\text { derangement }\end{array}$ & $0.6-1.0$ & $15-18$ & $>39$ & $2,000-4,000$ & $<1.5$ & 2 & $7-10$ \\
\hline $\begin{array}{l}\text { Severe } \\
\text { derangement }\end{array}$ & $<0.60$ & $>18$ & $>54$ & $>4,000$ & $<1$ & 3 & $>10$ \\
\hline
\end{tabular}

Abbreviations: APTT, activated partial thromboplastin time; DIC, disseminated intravascular coagulation; PT, prothrombin time. 


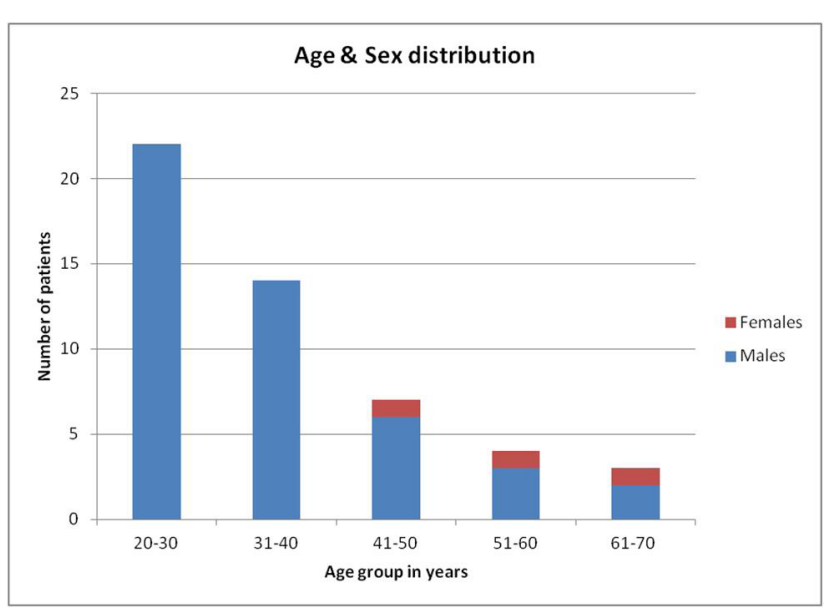

Fig. 1 Age and sex structure of study population.

\section{Prehospital Time of Patients}

Eighty percent of the patients were brought within 3 hours of trauma to the hospital. Another $12 \%$ were brought within 9 hours.

\section{GCS at Presentation}

Twenty-six (52\%) patients had MHI with GCS 9 to 13 and 24 patients had SHI having GCS $<8$ at presentation. The mean GCS was 12.23 and 5.75 in MHI and SHI patients, respectively. The overall mean GCS at presentation in the hospital was 9.12.

\section{DIC Score of the Patients}

Twelve patients (24\%) had a DIC score of 0 to 3. Twenty-two (44\%) patients had DIC score of 4 to 6 while 16 (32\%) patients had DIC score of 7 to 10 . In total, $76 \%$ of the patients had moderate to severe DIC scores.

\section{Management}

The various CT characteristics in population are depicted in pie-chart (-Fig. 2). Forty-two (84\%) patients were conservatively treated while $8(16 \%)$ patients underwent surgical intervention. Six patients of the SHI group and two of MHI were operated on.

\section{Outcome of the Patients}

Twenty-four patients with MHI were discharged with GOS 5 and two deaths were noted. On the other hand, 19 patients with SHI died, 4 were discharged with GOS 5 and one remained vegetative (GOS 2). Of the eight patients who underwent surgery four were discharged with GOS 5 , one with GOS 3, and three patients expired after surgery.

The patients with SHI were divided into two groups. The first group included 20 patients and had GOS 1 or GOS 2. The second group included four patients and had GOS 5. $p$-Value for DIC score was $<0.001$ and is statistically significant. $p$-Value in both PT and APTT was $<0.05$ and was significant. However, it was not significant for D-dimer, fibrinogen, and platelet counts ( - Table 2).

In patients with MHI, $p$-value in case of DIC score, platelet count, APTT, and D-dimer was $<0.001$ and was highly significant. $p$-Value in PT was $<0.05$ and found to be statistically significant, however, it was not significant for fibrinogen (-Table 3).

In patients with $\mathrm{MHI}, 62 \%$ of the study population had coagulopathy while $96 \%$ of the patients with SHI were found to have coagulation abnormalities ( - Fig. 3 ).

\section{Follow-Up}

Two patients had facial nerve palsy at presentation which persisted at 1 month of follow-up. However, it recovered in one patient at 3 months' follow-up. No further mortality was noted.

\section{Discussion}

The incidence of head injury has exponentially increased in present times primarily due to an increase in the number of vehicles plying on the road. ${ }^{22}$ Motor vehicle accidents, assault, and fall are three major modes of TBI. Most of the studies have shown accidents as the most common mode of injury. ${ }^{13,23}$ The present study found RTA as the primary cause of TBI in $72 \%$ of the cases which may be ascribable to negligence in following the traffic norms. This is in contrast to western studies which have a relatively lower incidence of RTA due to better education, cognizance, and strict traffic regulations. In developing countries like India, safety and awareness regarding traffic regulations is still a matter of grave concern.

Most of the patients in the study were young between the ages of 20 to 40 years (72\%) and predominantly males (94\%) probably because this age group is more involved in outdoor activities, alcohol intoxication, driving, and other differential gender functions in India. In systemic review and meta-analysis of 82 studies, Nguyen et al ${ }^{24}$ reported most TBIs among males and in the adult population. A similar data has been reported by Frost et $\mathrm{a}^{25}$ in their meta-analysis and many other authors too. ${ }^{26-29}$

\section{Coagulopathy in TBI}

The factors responsible for coagulopathy in TBI patients are probably different from extracranial injury. Although isolated TBI does not have massive blood loss to induce coagulopathy, still it is commonly seen in clinical practice. ${ }^{30}$ This suggests that TBI-induced coagulopathy follows a distinct pathogenic pathway that remains elusive. This also explains why the treatment and prevention of coagulopathy in TBI largely remains ineffective even today. ${ }^{31}$

The coagulation abnormalities in TBI have been studied earlier; however, the majority of them have included patients who sustained extracranial trauma too. The scoring system of ISTH was reviewed. Authors also added APTT in the study, the usefulness of which has been reported by multiple studies including Bakhtiari et al. ${ }^{32}$ Yuan et al ${ }^{33}$ also observed a significant correlation of APTT with poor outcome and mortality compared with other coagulation parameters.

We also noticed approximately $80 \%$ of the patients reported within 6 hours of trauma which is remarkable in this part of our developing country. Though the prehospital time is less in metro cities of the country. ${ }^{34}$ Hulka et al ${ }^{6}$ reported coagulopathy in TBI as early as first hour. Hence, the need 
Table 2 Comparison of mean values and SD of DIC score as well as individual laboratory tests in expired and discharged patients of the SHI group

\begin{tabular}{|l|l|l|l|l|}
\hline Parameter & $\begin{array}{l}\text { Expired or vegetative } \\
(\text { Group 1) } \\
(\boldsymbol{n}=\mathbf{2 0})\end{array}$ & $\begin{array}{l}\text { Discharged } \\
(\text { Group 2) } \\
(\boldsymbol{n}=\mathbf{4})\end{array}$ & $p$-Value & Mean value \\
\hline DIC score & $6.3 \pm 1.97$ & $4.0 \pm 2.44$ & $<0.001$ & $5.91 \pm 2.18$ \\
\hline Platelet & $1.64 \pm 0.58$ & $1.55 \pm 0.31$ & $>0.05$ & $1.63 \pm 0.54$ \\
\hline PT & $15.25 \pm 2.98$ & $12.92 \pm 1.48$ & $<0.05$ & $14.87 \pm 2.90$ \\
\hline APTT & $35.84 \pm 6.38$ & $28.8 \pm 3.85$ & $<0.05$ & $34.67 \pm 6.53$ \\
\hline Fibrinogen & $0.71 \pm 0.84$ & $0.40 \pm 0.284$ & $>0.05$ & $0.66 \pm 0.65$ \\
\hline D-dimer & $2812 \pm 1351$ & $2616 \pm 1703.86$ & $>0.05$ & $2779.73 \pm 1375.57$ \\
\hline
\end{tabular}

Abbreviations: APTT, activated partial thromboplastin time; DIC, disseminated intravascular coagulation; PT, prothrombin time; SD, standard deviation; SHI, severe head injury.

Table 3 Comparison of DIC score as well as individual laboratory tests in expired and discharged (GOS 3-5) patients of the MHI group

\begin{tabular}{|l|l|l|l|l|}
\hline Parameter & $\begin{array}{l}\text { Expired } \\
(\text { Group 1, } \boldsymbol{n}=2)\end{array}$ & $\begin{array}{l}\text { Discharged } \\
(\text { Group 2, } \boldsymbol{n}=24)\end{array}$ & $p$-Value & Mean value \\
\hline DIC score & $8.0 \pm 1.4$ & $3.92 \pm 2.33$ & $<0.001$ & $4.23 \pm 2.51$ \\
\hline Platelet & $0.9 \pm 0.42$ & $1.75 \pm 0.328$ & $<0.001$ & $1.69 \pm 0.40$ \\
\hline PT & $17.05 \pm 1.76$ & $13.75 \pm 2.13$ & $<0.05$ & $14.01 \pm 2.26$ \\
\hline APTT & $24.05 \pm 4.03$ & $34.93 \pm 10.71$ & $<0.001$ & $34.1 \pm 10.72$ \\
\hline Fibrinogen & $0.47 \pm 0.60$ & $0.68 \pm 0.66$ & $>0.05$ & $0.66 \pm 0.78$ \\
\hline D-dimer & $4122 \pm 883.17$ & $1829.23 \pm 1385.15$ & $<0.001$ & $2005.63 \pm 1478.05$ \\
\hline
\end{tabular}

Abbreviations: APTT, activated partial thromboplastin time; DIC, disseminated intravascular coagulation; GOS, Glasgow Outcome Scale; MHI, moderate head injury; PT, prothrombin time.

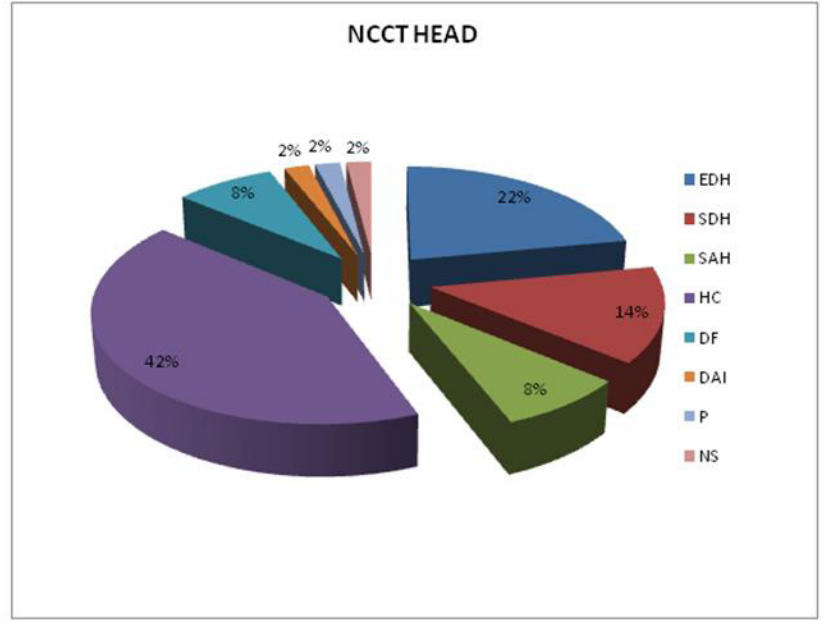

Fig. 2 Computed tomography findings along with their case distribution. DAl, diffuse axonal injury; DF, depressed fracture; EDH, extradural haematoma; HC, haemorrhagic contusion; NS, non specific (mixed haemorrhage); P, Pneumocephalus; SAH, subarachnoid haemorrhage; SDH, subdural haematoma.

for urgent medical attention in TBI cannot be overemphasized. On the other hand, the onset of coagulation abnormalities can be delayed up to 72 hours of $\mathrm{TBI}^{2}$ or up to 5 days. ${ }^{35}$ Our study, however, did not find a significant association of prehospital time with the development of coagulopathy.

Platelet dysfunction in TBI is now being increasingly recognized. However, the mechanism related to their activation

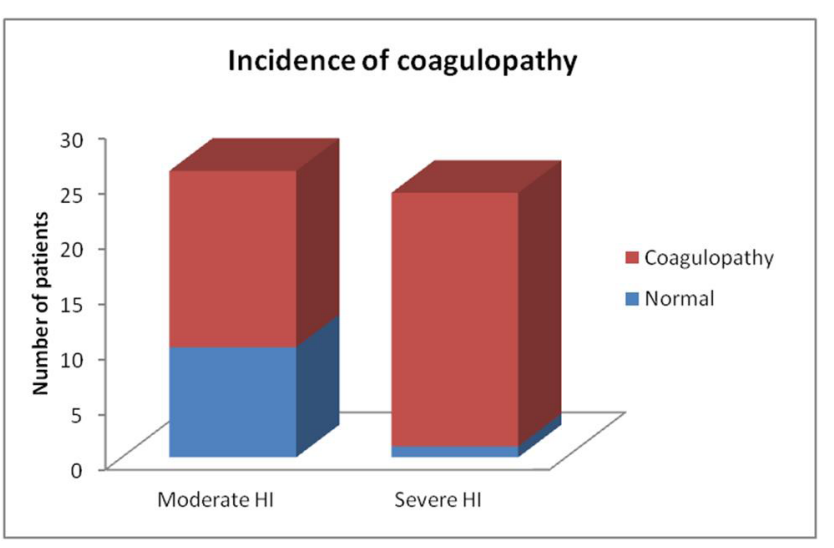

Fig. 3 Incidence of coagulopathy in moderate head injury (MHI) and severe head injury.

and dysfunction is poorly understood. ${ }^{36}$ Several studies have found a significant prevalence of platelet dysfunction in severe TBI. ${ }^{36,37}$ Wohlauer et $\mathrm{al}^{38}$ reported early platelet dysfunction and significant differences in the platelet response between trauma patients and healthy volunteers. The response of the platelets in TBI is not related to platelet count. ${ }^{37}$ Though many researchers have shown thrombocytopenia associated with TBI and poor outcomes. ${ }^{39,40}$ In our study, we did not find significance of platelet count with the severity of TBI. Even in severe TBI, the platelet count remained $>100,000$. We found high statistical significance of platelet count in MHI when outcomes were compared. We 
Table 4 Statistical result of DIC score and GOS in MHI and SHI

\begin{tabular}{|l|l|l|l|}
\hline & DIC score & GOS & $p$-Value \\
\hline Severe head injury & $5.91 \pm 2.18$ & $1.54 \pm 1.98$ & $<0.001$ \\
\hline Moderate head injury & $4.23 \pm 2.51$ & $4.62 \pm 1.09$ & $>0.05$ \\
\hline All patients & $5.04 \pm 2.49$ & $3.1 \pm 1.9$ & $<0.001$ \\
\hline
\end{tabular}

Abbreviations: DIC, disseminated intravascular coagulation; GOS, Glasgow Outcome Scale; MHI, moderate head injury; SHI, severe head injury.

suggest that thrombocytopenia may not be associated with isolated head injury patients and platelet dysfunction may be the cause of coagulopathy. However, a large prospective/randomized trial is required for its validation.

PT is a measure of the function of the extrinsic and common coagulation pathways. The expired patients of both the moderate and severe TBI group had higher international normalized ratio (INR) values compared with discharged ones. The PT was found to be a statistically significant parameter in this study for both moderate and severe TBI. Saggar et $\mathrm{al}^{41}$ also reported higher INR values in expired (2.28 \pm 0.59$)$ patients compared with the discharged group (1.33) \pm 0.47 . The IMPACT study (International Mission on Prognosis and Analysis of Clinical Trials) in TBI found that prolonged PT at admission was present in $26 \%$ of patients and was associated with a $64 \%$ increase in mortality risk. ${ }^{12}$ Various other studies also found PT to be the most consistent coagulation abnormality in TBI. ${ }^{35,42}$

APTT was found to be a significant predictor of prognosis in this study and was found to be significant in both moderate and severe TBI among expired and discharged patients. This parameter has been reported as prolonged by various studies. ${ }^{20,32,33,35,43}$ Multivariate logistic regression analysis by Yuan et $\mathrm{al}^{33}$ found INR > 1.25, and APTT > 36 seconds were independently associated with in-hospital mortality. Macleod et $\mathrm{l}^{42}$ too in his multiple regression model found PT and APTT as independent predictors of mortality.

D-dimer is a fragment of degradation products of cross-linked fibrin and is an indicator of ongoing fibrinolytic activity. This factor was found to be statistically significant in the MHI group; however, it was not significant in the case of SHI. The D-dimer concentration increases in head injury patients in comparison to other trauma patients. ${ }^{5}$ Kuo et al ${ }^{14}$ reported that $\mathrm{D}$-dimer values $>1,496 \mathrm{mcg} / \mathrm{dL}$ were associated with poor prognosis in head injury patients.

In the meta-analysis by Epstein et $a 1,{ }^{44}$ retrospective and prospective cohortstudies wereanalyzed and an incidence of $35.2 \%$ of coagulopathy in TBI patients was found. A meta-analysis of 34 studies by Harhangi et a ${ }^{10}$ reported an overall prevalence of coagulopathy in $32.7 \%$ after TBI. This incidence is very less compared with the present study which has observed $76 \%$ of coagulopathy in TBI cases which is similar to that reported by Affonseca et al. ${ }^{13}$ Saggar et $\mathrm{al}^{41}$ and Selladurai et $\mathrm{al}^{45}$ reported 63 and 38\% poor DIC score, respectively. The variation in the percentages of patients having such a wide range of DIC scores or coagulopathy can be explained based on differences in the severity of injuries of patients in the different studies, different criteria used for coagulopathy, and different combinations of laboratory parameters used. The incidence is also dependent upon the cutoff laboratory value and the time lag between sample collection and trauma.

\section{Outcome}

In the MHI group the mortality was $8 \%$ while in the SHI group it was $79 \%$. In those who developed coagulopathy, the mortality was $55 \%$. The overall mortality was $42 \%$. The prevalence of acute traumatic coagulopathy is directly associated with the severity of brain injury. van Gent et $\mathrm{al}^{2}$ found coagulopathy in patients with TBI to be associated with the progression of hemorrhagic injury, surgical intervention, and increased in-hospital mortality.

\section{Coagulopathy and GCS}

The study observed severe coagulation abnormalities in patients with GCS $<8$. This finding has implication in terms of predicting coagulopathy in TBI. May et $\mathrm{al}^{46}$ reported coagulopathy in $81 \%$ of patients having GCS $<6$ and $100 \%$ in those having GCS $<3$. Pahatouridis et $\mathrm{al}^{19}$ observed a correlation of severity of head injury with the severity of coagulation disorder and reported that patients with lower GCS were at higher risk of coagulation derailments. van Gent et $\mathrm{al}^{2}$ found lower mean GCS (6.1) and worse prognosis in patients developing coagulopathy within 24 hours of trauma compared with patients without coagulopathy (10.1). Talving et al ${ }^{47}$ reported that GCS score of $<8$ is an independent risk factor for coagulopathy in isolated head injuries and TBI coagulopathy was associated with longer intensive care unit stay and 10 times increased mortality. These reports suggest that coagulopathy and GCS are interdependent.

\section{Correlation of DIC Score to Outcome (GOS)}

DIC score was found as an important predictor of the outcome of patients. On the statistical analysis of DIC score with GOS, the $p$-value was $<0.001$ which is highly significant ( - Table 4). We found that patients with poor DIC scores $(>4)$ within the first 24 hours had a worse prognosis (GOS 1). Affonseca et $\mathrm{al}^{13}$ and Greuters et $\mathrm{al}^{20}$ also observed that the presence of coagulopathy was related to a poor prognosis and on correlating the coagulopathy with the outcome the observed $p$-value was $<0.01$ in the former and $<0.04$ in the latter study. Macleod et $\mathrm{al}^{42}$ also reported early coagulopathy as a predictor of mortality in trauma.

\section{Merits of the Study}

The study has included GCS and GOS both in the clinical assessment of the patients and excluded patients who had other associated injuries. The patients with comorbidities were also excluded. Follow-up clinical assessment was done. 
The laboratory parameters used for the assessment of coagulopathy in the study are routinely available and can be used in institutions having basic laboratory facilities.

\section{Limitations of the Study}

Interval or sequential assessments of laboratory parameters were not done. As the time of sample collection affects the laboratory parameters, standardization of timing should be done to cut the observer bias. Thromboelastography parameters may have been included in this study.

\section{Conclusion}

The patients of isolated head injury are at high risk of developing coagulation abnormalities. Coagulopathy is directly associated with the severity of TBI, GCS, and is independently associated with poor outcome. DIC score is a useful parameter in the prediction of prognosis of head injury patients. The timely intervention in such patients can help improve prognosis. The analysis of coagulation parameters are useful predictors of outcome and can be used to explain the relatives about prognosis and course of the patient during the hospital stay.

\section{Conflict of Interest}

None declared.

\section{References}

1 Laroche M, Kutcher ME, Huang MC, Cohen MJ, Manley GT. Coagulopathy after traumatic brain injury. Neurosurgery 2012; 70(6):1334-1345

2 van Gent JAN, van Essen TA, Bos MHA, Cannegieter SC, van Dijck JTM, Peul WC. Coagulopathy after hemorrhagic traumatic brain injury, an observational study of the incidence and prognosis. Acta Neurochir (Wien) 2020;162(2):329-336

3 Stein SC, Smith DH. Coagulopathy in traumatic brain injury. Neurocrit Care 2004;1(4):479-488

4 van der Sande JJ, Emeis JJ, Lindeman J. Intravascular coagulation: a common phenomenon in minor experimental head injury. J Neurosurg 1981;54(1):21-25

5 Scherer RU, Spangenberg P. Procoagulant activity in patients with isolated severe head trauma. Crit Care Med 1998;26(1): 149-156

6 Hulka F, Mullins RJ, Frank EH. Blunt brain injury activates the coagulation process. Arch Surg 1996;131(9):923-927, discussion 927-928

7 Brohi K, Cohen MJ, Davenport RA. Acute coagulopathy of trauma: mechanism, identification and effect. Curr Opin Crit Care 2007;13(6):680-685

8 Cohen MJ, Brohi K, Ganter MT, Manley GT, Mackersie RC, Pittet JF. Early coagulopathy after traumatic brain injury: the role of hypoperfusion and the protein C pathway. J Trauma 2007;63(6):1254-1261, discussion 1261-1262

9 Kuo JR, Chou TJ, Chio CC. Coagulopathy as a parameter to predict the outcome in head injury patients-analysis of 61 cases. J Clin Neurosci 2004;11(7):710-714

10 Harhangi BS, Kompanje EJ, Leebeek FW, Maas AI. Coagulation disorders after traumatic brain injury. Acta Neurochir (Wien) 2008;150(2):165-175, discussion 175

11 Carrick MM, Tyroch AH, Youens CA, Handley T. Subsequent development of thrombocytopenia and coagulopathy in moderate and severe head injury: support for serial laboratory examination. J Trauma 2005;58(4):725-729, discussion 729-730

12 Van Beek JG, Mushkudiani NA, Steyerberg EW, et al. Prognostic value of admission laboratory parameters in traumatic brain injury: results from the IMPACT study. J Neurotrauma 2007;24(2):315-328

13 Affonseca CA, Carvalho LF, Guerra SD, Ferreira AR, Goulart EM. Coagulation disorder in children and adolescents with moderate to severe traumatic brain injury. J Pediatr (Rio J) 2007;83(3):274-282

14 Kuo JR, Lin KC, Lu CL, Lin HJ, Wang CC, Chang CH. Correlation of a high D-dimer level with poor outcome in traumatic intracranial hemorrhage. Eur J Neurol 2007;14(10):1073-1078

15 Nekludov M, Antovic J, Bredbacka S, Blombäck M. Coagulation abnormalities associated with severe isolated traumatic brain injury: cerebral arterio-venous differences in coagulation and inflammatory markers. J Neurotrauma 2007;24(1):174-180

16 Fuller G, Pattani H, Chalmers A, et al. Coagulopathy predicts poor outcome in traumatic brain injury. Crit Care 2008;12:126

17 Pereira EA, Green AL, Chandran H, Joshi SM, Shlugman D, Cudlip SA. Disseminated intravascular coagulation after isolated mild head injury. Acta Neurochir (Wien) 2009;151(11):1521-1524

18 Shahrokh Yousefzadeh C, Anosh Dehnadi M, Shahrokh E, Mohhammad S, Haniyeh Mohammadi M. A review of intraparenchymal hemorrhage and contusion progression in traumatic brain injury. Neurosurg Q 2010;20(2):65-67

19 Pahatouridis D, Alexiou GA, Zigouris A, Mihos E, Drosos D, Voulgaris S. Coagulopathy in moderate head injury. The role of early administration of low molecular weight heparin. Brain Inj 2010;24(10):1189-1192

20 Greuters S, van den Berg A, Franschman G, et al. ALARMBLEEDING investigators. Acute and delayed mild coagulopathy are related to outcome in patients with isolated traumatic brain injury. Crit Care 2011;15(1):R2

21 Alexiou GA, Pahatouridis D, Vulgaris S. Coagulopathy in traumatic brain injury. Injury 2011;42(1):113-, author reply 114

22 Gutman SA. Traumatic brain injury. In Pedretti LW, Early MB, eds. Occupational therapy: Practice skills for physical dysfunction. 5th ed. St. Louis, MO: Mosby;2001:671-701

$23 \mathrm{Gan} \mathrm{BK}, \mathrm{Lim} \mathrm{JH}, \mathrm{Ng} \mathrm{IH}$. Outcome of moderate and severe traumatic brain injury amongst the elderly in Singapore. Ann Acad Med Singapore 2004;33(1):63-67

24 Nguyen R, Fiest KM, McChesney J, et al. The international incidence of traumatic brain injury: a systematic review and meta-analysis. Can J Neurol Sci 2016;43(6):774-785

25 Frost RB, Farrer TJ, Primosch M, Hedges DW. Prevalence of traumatic brain injury in the general adult population: a meta-analysis. Neuroepidemiology 2013;40(3):154-159

26 Khan A, Prince M, Brayne C, Prina AM. Lifetime prevalence and factors associated with head injury among older people in low and middle income countries: a 10/66 study. PLoS One 2015;10(7):e0132229

27 Gardner AJ, Zafonte R. Neuroepidemiology of traumatic brain injury. Handb Clin Neurol 2016;138:207-223

28 Feigin VL, Theadom A, Barker-Collo S, et al. BIONIC Study Group. Incidence of traumatic brain injury in New Zealand: a population-based study. Lancet Neurol 2013;12(1):53-64

29 Eshete A, Taye F. Magnitude of severe head injury and its associated factors among head injury patients in Gedeo Zone, Southern Ethiopia: a two-year retrospective study. Ethiop J Health Sci 2018;28(3):323-330

30 Wafaisade A, Wutzler S, Lefering R, et al. Trauma Registry of DGU. Drivers of acute coagulopathy after severe trauma: a multivariate analysis of 1987 patients. Emerg Med J 2010; 27(12):934-939 
31 Zhang J, Zhang F, Dong JF. Coagulopathy induced by traumatic brain injury: systemic manifestation of a localized injury. Blood 2018;131(18):2001-2006

32 Bakhtiari K, Meijers JC, de Jonge E, Levi M. Prospective validation of the International Society of Thrombosis and Haemostasis scoring system for disseminated intravascular coagulation. Crit Care Med 2004;32(12):2416-2421

33 Yuan Q, Yu J, Wu X, et al. Prognostic value of coagulation tests for in-hospital mortality in patients with traumatic brain injury. Scand J Trauma Resusc Emerg Med 2018;26(1):3

34 Dharap SB, Kamath S, Kumar V. Does prehospital time affect survival of major trauma patients where there is no prehospital care? J Postgrad Med 2017;63(3):169-175

35 Lustenberger T, Talving P, Kobayashi L, et al. Time course of coagulopathy in isolated severe traumatic brain injury. Injury 2010;41(9):924-928

36 Davis PK, Musunuru H, Walsh M, et al. Platelet dysfunction is an early marker for traumatic brain injury-induced coagulopathy. Neurocrit Care 2013;18(2):201-208

37 Ploplis VA, Donahue DL, Sandoval-Cooper MJ, et al. Systemic platelet dysfunction is the result of local dysregulated coagulation and platelet activation in the brain in a rat model of isolated traumatic brain injury. J Neurotrauma 2014;31(19):1672-1675

38 Wohlauer MV, Moore EE, Thomas S, et al. Early platelet dysfunction: an unrecognized role in the acute coagulopathy of trauma. J Am Coll Surg 2012;214(5):739-746
39 Kweon JG, Hwang SK, Park YM, Kim SL. Coagulopathy in head injury. J Korean Neurosurg Soc 1991;20:406-413

40 Engström M, Romner B, Schalén W, Reinstrup P. Thrombocytopenia predicts progressive hemorrhage after head trauma. J Neurotrauma 2005;22(2):291-296

41 Saggar V, Mittal RS, Vyas MC. Hemostatic abnormalities in patients with closed head injuries and their role in predicting early mortality. J Neurotrauma 2009;26(10):1665-1668

42 MacLeod JB, Lynn M, McKenney MG, Cohn SM, Murtha M. Early coagulopathy predicts mortality in trauma. J Trauma 2003;55(1):39-44

43 Allard CB, Scarpelini S, Rhind SG, et al. Abnormal coagulation tests are associated with progression of traumatic intracranial hemorrhage. J Trauma 2009;67(5):959-967

44 Epstein DS, Mitra B, O’Reilly G, Rosenfeld JV, Cameron PA. Acute traumatic coagulopathy in the setting of isolated traumatic brain injury: a systematic review and meta-analysis. Injury 2014;45(5):819-824

45 Selladurai BM, Vickneswaran M, Duraisamy S, Atan M. Coagulopathy in acute head injury-a study of its role as a prognostic indicator. Br J Neurosurg 1997;11(5):398-404

46 May AK, Young JS, Butler K, Bassam D, Brady W. Coagulopathy in severe closed head injury: is empiric therapy warranted? Am Surg 1997;63(3):233-236, discussion 236-237

47 Talving P, Benfield R, Hadjizacharia P, Inaba K, Chan LS, Demetriades D. Coagulopathy in severe traumatic brain injury: a prospective study. J Trauma 2009;66(1):55-61, discussion $61-62$ 